\title{
Modelos Estadísticos del Riesgo y Riesgo de los Modelos Estadísticos
}

\author{
A. JAVIER IZQUIERdo \\ Departamento de Sociología I \\ UNED
}

Si se piensa en los delincuentes que habitaron los mercados financieros durante los años 90 probablemente nos vendrán a la cabeza los nombres de operadores de bolsa como Joseph Jett de Keader Peabody, Nick Leeson de Barings o Yasuo Hamanaka de Sumimoto. Asi que tal vez sorprenda saber que en estos años quien realmente ha destacado es un delincuente de una especie bien diferente: los modelos matemáticos de valoración de productos derivados. (Falloon, 1998: 24).

\section{INTRODUCCIÓN}

En un nuestro hiper-tecnologizado mundo contemporáneo, la vieja querella de la indagación pública enfrentada al secretismo y la corrupción informativas -los juegos históricos de estrategia entre el detective y el defraudador (Kaye, 1995) o el perito y el falsificador (Grafton, 1990) - alcanza uno de sus más altos niveles de sofisticación en la batalla global por la definición de procedimientos normalizados de supervisión pública de riesgos financieros. Comparable solo con el barroco tapiz que tejen los sistemas de seguridad informática para intentar protegerse del ataque descentralizado de la horda hacker (Shimomura y Markoff, 1995), la batalla que libran el ingeniero y el supervisor financiero por la definición de términos como "error aleatorio», «suceso extraordinario", «accidente imprevisible», «negligencia profesional» o «imprudencia empresarial», nos ofrece una de las variantes más intrincadas de la dialéctica clásica del cono- 
cimiento autorizado corrompido en falsificación estratégica y vuelto de nuevo a reciclar como crítica reflexiva.

Tomando como referente un conjunto de trabajos sociológicos recientes que se han ocupado de explorar empíricamente y analizar teóricamente las formas novedosas de acción social que se desarrollan en el interior de entornos tecnológicos de alto riesgo ${ }^{1}$, la investigación que he llevado a cabo durante los últimos años sobre los avatares científicos, económicos, jurídicos y políticos del comportamiento innovador en el mundo de las finanzas contemporáneas (Izquierdo, 1999 b) se proponía circunscribir sociológicamente uno de los dilemas morales más ubicuos y peliagudos que afronta la vida en común en las sociedades industriales avanzadas: el problema de cómo y en qué medida es posible atribuir identidades -en forma de «autorías» individual o grupalmente circunscritas- y responsabilidades -en forma de grados escalables de «mérito» o "culpa»- en un entorno donde el azar, esto es, tanto la casualidad positiva que conocemos como «suerte» como la fortuna negativa que se nos aparece como «error», es siempre, en cierto modo, demasiado probable. En el ambiente «exponencialmente innovador» de nuestros mercados de capital contemporáneos (Merton, 1995), se hace particularmente difícil identificar primero y distinguir después, desde el punto de vista de un criterio teórico apriorístico, la clase de comportamientos decididamente no rutinarios que en otras circunstancias menos borrosas catalogaríamos de forma excluyente bien como «inteligentes», bien como «imprudentes» o aun «temerarios», bien sencillamente de «delicitivos» e incluso abiertamente «criminales».

Descendiendo a un nivel más específico de reflexión sociológica, lo que se pretende ofrecer aquí es una interpretación original de un conocido efecto perverso de «reflexividad social de tipo estadístico» ${ }^{2}$ que los profesionales de la gestión de riesgos financieros conocen como riesgo de modelización o riesgo de modelo (model risk) (Derman, 1996a). Con este término, los expertos en control de riesgos financieros hacen referencia a la probabilidad de incurrir en pérdidas de negociación bursátil (trading losses) directamente asociada con la utilización de un determinado modelo computacional de valoración de activos de capital por los gestores y operadores de un banco o sociedad de inversiones. El examen de la controversia pública sobre los criterios y métodos de evaluación experta de los riesgos de modelización econométrica del riesgo financiero nos demuestra que también en este particular universo cultural es posible plantearse la cuestión fundamental del doble estatuto funcional de los dispositivos y modelos formales de conocimiento público, almacén último del criticismo racional y progresivo a la vez que alimento indispensable para el artificio pseudo-científico y, lo que es

1 Veánse los trabajos de Gusfield (1981), Perrow (1984) y Scheppele (1991). Tres útiles revisiones de la ingente literatura sociológica sobre la percepción y la prevención del riesgo son las de Heimer (1988), Douglas (1996) y Clarke y Short (1993).

2 En otro lugar he definido taquigráficamente la reflexividad social de tipo estadístico como «el uso retroactivo (positivo para confirmar o negativo para rectificar) por parte de los sujetos, de un tipo particular de información sobre su entorno, las cifras estadísticas, como input cognitivo en sus procesos individuales de toma de decisiones.» (Izquierdo, 1999a: 540). Para una exposición más detallada de la substancia teórica de este término véase Izquierdo (1999b: 277ss). 
peor, cohartada tecnocrática para la suplantación de las libertades políticas y, en última instancia, la deshumanización de nuestras instituciones sociales. Y es que, como ha observado Francis Chateauraynaud en su impagable estudio sobre las controverias de responsabilidad profesional, «desde el punto de vista de las teorías del riesgo, las expresiones morales no son ya pertinentes para asegurar la reglamentación de las situaciones. La objetividad de la regla de juicio y del procedimiento de su puesta en práctica permiten un tratamiento de los hecho externo al juicio moral ordinario.» (Chateauraynaud, 1991: 405).

Nuestro análisis comparte así buena parte del espíritu y, en menor medida, de la letra del proyecto sociológico de exploración del abanico de competencias cognitivas y morales que, en el contexto pragmático de las situaciones concretas que todos afrontamos en la vida ordinaria, sustancian eso que llamamos el «sentido común de la justicia», iniciado a principios de la década de los 80 por Michael Pollack, Luc Boltanski y Laurent Thévenot, animadores del Groupe de Sociologie Politique et Moral de la Ecole de Hautes Etudes en Sciences Sociales de París. La obra fundadora de este programa de investigaciones, De la justification. Les économies de la grandeur (Boltanski y Thévenot, 1991), expone un interesante modelo combinatorio de los diferentes tipos de servidumbres (contraintes) de carácter semiótico y también físico a los que deben plegarse un tipo particularmente complejo de acciones humanas, las acciones en régimen de justificación que pretenden vincular eventos particulares a la búsqueda de una entidad metafísica, un bien superior común, para poder ser efectivamente puestas a prueba de forma legítima por aquellas otras acciones características que se desarrollan en régimen de crítica. Las cuales acciones, a su vez, han de cumplir simétricamente con exactamente los mismos requisitos convencionales de formalización argumentativa y objetual para poder pasar del estatuto de quejas privadas al de denuncias públicas.

Si bien el carácter excesivamente abstracto y genérico de los seis modelos de mundos de valor (mondes de grandeur) formulados por Boltanski y Thévenot (mundo cívico, industrial, inspirado, opinático, doméstico y mercantil) no se presta en principio a demasiadas alegrías descriptivas (Dodier y Baszanger, 1997: 55), investigaciones empíricas posteriores llevadas a cabo en el marco de esta propuesta teórica han contribuido de forma decisiva a especificar teórica y metodológicamente el modelo de las économas de la grandeur para poder abordar de forma efectiva diferentes terrenos investigadores concretos. Más específicamente, para poder describir, según un esquema análogo de tratamiento simétrico de los requisitos de justificación y de crítica, un tipo singular de situaciones críticas empíricas - dentro del cual es plausible adscribir la disputa concreta que aquí nos ocupa- donde lo que está en juego es la formulación por parte de los actores de juicios legítimos sobre el grado de «humanidad» o «moralidad» mínima que poseen aquellos cursos de acción social donde, paradójicamente, son mayormente las cosas y no las personas las que entran en contacto entre sí. En este sentido cabe destacar principalmente el detallado estudio (de cuya lectura se ha beneficiado enormemente este trabajo) llevado a cabo por Francis Chateauraynaud (1991) sobre la codificación de diferentes concepciones complementarias y alternativas de la responsabilidad individual y el error sistémico en el con- 
texto de aquellas disputas colectivas abiertas a raíz de actos explícitos de acusación por negligencia profesional ${ }^{3}$.

En lo que sigue a continuación nos serviremos de un estudio de caso particular sobre la emergencia de un conjunto de normas públicas de control de calidad de modelos estadísticos del riesgo en la industria financiera internacional para ejemplificar y analizar esta paradoja cultural tan característica de nuestra modernidad avanzada: la comunión entre búsqueda crítica de la autenticidad y producción informada de apariencias, que tiene su origen en la substitución progresiva de los hábitos y principios convencionales del juicio moral por modelos objetivos, formalizados de conocimiento experto de carácter forense y pericial.

\section{LA ECONOMÍA POLÍTICA DE LOS MODELOS ECONOMICOS DEL RIESGO}

Como fue expuesto con claridad meridiana por el Juez Kaufman del Tribunal Supremo de EE.UU., en la fundamentación de su resolución de un caso de tráfico de información privilegiada (Securities Exchange Commision vs. Materia) juzgado en 1985, los mercados organizados de capital son arenas sociales donde las restricciones tecno-económicas que gobiernan la producción y la difusión de conocimiento abstracto (modelos teórico-matemáticos) e información cuantitativa (datos) se sufren con la mayor de las intensidades:

«Nuestra era ha sido justamente calificada, y podría muy bien ser recordada, como la 'era de la información'. Francis Bacon reconoció hace casi cuatrocientos años que 'el conocimiento es poder' Pero sólo durante la última generación se ha convertido el conocimiento en auténtica moneda de curso. Y en ningún sitio es esta mercancía tan valiosa o volátil como en el mundo de las altas finanzas, donde los datos valen fortunas mientras permanecen secretos pero pueden no valer nada una vez revelados» (citado en Boyle, 1996: 81).

Sin embargo, los diferenciales de información sustantivos, aquéllos producidos por el conocimiento privado de hechos que aun no han salido a la luz pública -cuya figura límite, el famoso trafico de información interna o privilegiada (insider trading) es considerado una actividad ilegal por las leyes bursátiles de una gran mayoría de Estados- constituyen un factor cada vez menos decisivo como fuente de ventaja competitiva en las transacciones financieras. En la actualidad, la parte del león de las estructuras de competencia financiera tiene como base un diferencial informacional de naturaleza formal que tiene su origen en la actividad innovadora $-\mathrm{y}$ por tanto, en la diversidad resultante- en materia de métodos y modelos calculísticos de procesamiento de números financieros. En

${ }^{3}$ Otra interesante aportación al desarrollo teórico, metodológico y empírico de este programa de investigaciones es la monografía de Nicolás Dodier (1995) sobre el virtuosismo técnico y sociológico que demuestran los operarios industriales en la laboriosa tarea cotidiana de ajuste adaptativo a un entorno económico, organizacional y tecnológico cambiante. 
un mundo, como el de la industria de servicios financieros avanzados, donde los datos brutos de cantidades y precios de negociación son en su mayor parte información de dominio público, los diferenciales de rentabilidad de negocio relevantes son efecto de la rapidez, robustez y fiabilidad computacional de los diversos modelos estadístico-econométricos entre los que los traders han de elegir para llevar a cabo la medición y valoración eficiente de riesgos financieros.

En este sentido es útil distinguir entre dos tipos de usos económicos de los modelos matemáticos del riesgo financiero. En primer lugar se observa que los agentes llevan a cabo lo que podríamos llamar un uso industrial de los modelos, que se asociaría con los costes fijos de I+D y las correspondientes rentas monopolísticas a largo plazo que se derivan de estrategias competitivas desplegadas por las diversas firmas de servicios financieros en el incipiente mercado de los sistemas computacionales de gestión automatizada de riesgos bursátiles, con toda la plétora de subproductos que lo acompaña en la forma de servicios de mantenimiento, consultoría experta, etc. Dentro del sistema industrial de proveedores globales de productos y servicios financieros avanzados, el «asunto tecnológico» de la fiabilidad de las inferencias econométricas y el «asunto político» de la adecuación de las dotaciones legales de capital inmovilizado de carácter precautorio (vid. infra) se articulan de manera característica en la forma de una «batalla de estándares» en la que cada agente trata de promover su sistema de gestión local al estatus de norma tecnológica universal (Besen y Farrell. 1994).

Pero a corto plazo la preocupación fundamental de los usuarios últimos de estos sistemas expertos es el uso financiero directo de estos modelos de control de riesgos: las ganancias o pérdidas de eficiencia asignativa en materia de reservas de capital que pueden obtenerse casi inmediatamente como consecuencia de disponer de un modelo matemático más preciso para el ajuste de los riesgos de inversión. Estas ganancias en la productividad del capital se traducen como un ahorro neto de recursos que las diferentes técnicas de cálculo econométrico prometen a las empresas al minimizar la cantidad de reservas de capital inmovilizadas (el «capital muerto») que se considera necesaria en cada momento para asegurarse contra el riesgo de quiebra empresarial.

Dentro de esta segunda dimensión económica de la actividad de investigación y desarrollo en materia de modelos estadísticos del riesgo financiero es donde puede localizarse la actual controversia política de ámbito internacional en materia de estándares de supervisión financiera que vincula la corrección de los modelos internos de gestión de riesgos empleados por las corporaciones bancarias más activas en los mercados mundiales de capital con la suficiencia de sus reservas preventivas. El nivel de los requisitos de capital (la razón entre fondos de reserva y activos de inversión) que se exige a los grandes intermediarios financieros que operan en los mercados globales de derivados es un factor de influencia clave sobre la competitividad de su negocio.

En un universo donde la volatilidad de los valores de inversión negociables afecta de manera cada vez más acusada a los parámetros económicos clásicos de la industria bancaria (tipos de interés crediticio, tasas de impagados, etc.), la cifra al uso de la cantidad de activo sobre pasivo en el balance financiero tradicional de estos intermediarios necesita ser complementada con nuevos tipos de datos 
contables estandarizados referidos al riesgo de sus operaciones bursátiles. Y estos nuevos datos dan lugar a un nuevo cálculo de reservas de capital preventivo. A causa de las nuevas regulaciones internacionales adoptadas en materia de supervisión bancaria (véase más abajo), el cálculo teórico de las pérdidas esperadas por operaciones de trading bursátil que lleva a cabo internamente cada intermediario financiero tiene un impacto directo y aun considerable sobre el nivel efectivo de reservas de capital que necesitan para proteger completamente a sus propietarios (accionistas y acreedores) ante la eventualidad de grandes movimientos adversos en los precios financieros propagados a gran escala. Y, a través de la determinación del nivel de reservas, sobre la rentabilidad financiera agregada del negocio, ya que, si el drenaje de fondos que se precisa para alcanzar el nivel mínimo de protección contra el riesgo de fluctuación bursátil es extremadamente grande, se puede llegar a poner en peligro en última instancia la viabilidad financiera de la compañía. La necesidad de dotar a la empresa de mayores reservas de capital reduce los fondos disponibles para invertir en los mercados y por tanto reduce la rentabilidad esperada del negocio y, en su caso, el valor de mercado que los inversores asignan a las acciones de la compañía. Con el valor accionarial disminuido las agencias de rating rebajarán la calificación de su deuda, con lo que la compañía entrará definitivamente en la espiral suicida que conduce a intentar compensar el pago de intereses más altos por su deuda con la adquisición de valores de alta rentabilidad -y por tanto de alto riesgo- y termina con nuevas acciones supervisoras en el sentido de elevar aún más el nivel de sus reservas.

Pero la actividad de elaboración cultural que llevan a cabo los constructores de modelos matemáticos del riesgo financiero es susceptible todavía de un tercer tipo, aun más explícito y directo, de análisis económico en términos de costebeneficio y riesgo-rentabilidad: su captura en términos de un tipo de riesgo financiero de segundo orden conocido en el mundo de los analistas, ingenieros y operadores financieros como riesgo de modelo.

\section{UN RIESGO DE SEGUNDO ORDEN: EL «RIESGO DE MODELO»}

Una reputada consultora en materia de tecnología financiera con base en Nueva York, la firma Capital Market Risk Advisors (CMRA), calificaba en uno de sus últimos informes al ejercicio de 1997 como el «año de las pérdidas causadas por los modelos» (Falloon, 1998). La consultora atribuía pérdidas por valor de 2.7 billones de dólares, esto es, el equivalente al $40 \%$ de las pérdidas totales causadas por los productos derivados durante aquel año, a errores en la construcción teórica o utilización práctica de los modelos econométricos de valoración. Esta misma firma estimaba que, de un total de 23.8 billones de pérdidas acumuladas por operaciones con derivados entre 1987 y 1997, 4.7 billones de dólares podían atribuirse a la acción del riesgo de modelo: el riesgo de que los datos introducidos en el modelo, o sus premisas de partida o errores en los cálculos, tengan como consecuencia pérdidas financieras (Stix, 1998: 27). Así, por ejemplo, los errores de valoración cometidos durante el ejercicio de 1997 en la 
gestión matemática del libro de opciones sobre productos de renta fija del National Westminster Bank del Reino Unido le costaron a esta firma 123 millones de dólares. Del mismo modo, la pérdida de unos 50 millones de dólares por parte del Banco de Tokyo-Mitsubishi durante el mismo ejercicio se atribuye también al uso de un modelo econométrico incorrecto que sobrevaloraba la cartera de opciones en permutas de tipos de interés del banco. Finalmente, según el mismo informe de CMRA, la inadecuación de las hipótesis estadísticas de sus modelos de valoración, unida a una supervisión defectuosa de la calidad de los datos introducidos en ellos, condujo a la Unión de Bancos Suizos a unas pérdidas en su libro de derivados de alrededor de 240 millones de dólares (Falloon, 1998: 24).

El riesgo de modelo ha sido definido como aquel tipo de riesgo financiero que «resulta de la especificación inapropiada de un modelo teórico o del uso de un modelo apropiado en un marco inadecuado o para un propósito equivocado.» (Gibson et. al., 1998: 5). Los riesgos (cuantificables) e incertidumbres (no cuantificables) que implica de manera específica la práctica de la investigación científica organizada y sistemática (modelización, estimación, contraste, diagnóstico) de los procesos económicos que tienen lugar en el interior de los mercados financieros (Izquierdo, 1999b, cap. 2) constituyen los auténticos «fundamentos», en la acepción teórico-económica del término, que determinan el valor de mercado del conocimiento financiero formalizado, entendido ahora como recurso competitivo estratégico en el negocio global de la industria de servicios financieros avanzados ${ }^{4}$. Por tanto, los múltiples determinantes económicos del riesgo de modelo se identifican con el conjunto prácticamente infinito de maneras de construir un modelo teórico erróneo del movimiento de los precios bursátiles o bien de emplear un modelo correcto de un modo incorrecto (Derman, 1996b).

En una primera aproximación puramente económica, externa, el concepto de riesgo de modelo nos permite dar cuenta del hecho de que existen diferentes tipos de modelos econométricos formalizados para la valoración de activos de inversión cuyo uso puede dar lugar a una dispersión enorme en los precios teóricos de un mismo producto financiero. A medida que la discrepancia entre la horquilla de precios teóricos de oferta y demanda de valores se acaba resolviendo como consecuencia de la negociación mercantil, el uso de un determinado precio teórico como insumo en el proceso de toma de decisión que conduce a cerrar una determinada transacción financiera se acaba revelando como una de las causas eficientes del éxito o el fracaso económico de un operador en el mercado.

Un segundo enfoque posible de este fenómeno es su interpretación desde el punto de vista de la metodología de la modelización econométrica. Este enfoque pone el acento sobre la existencia de diferentes tipos y niveles de error en la práctica de la modelización financiera: errores cometidos en la formulación de las hipótesis teóricas de base, en la traducción de estas hipótesis en lenguaje algebraico, en la elección de la muestra estadística relevante, en la realización de los

\footnotetext{
${ }^{4}$ Como lo ha expresado un conocido economista: «El acto de construir un modelo implica una pérdida además de una ganancia... [es decir] también existen costes [de modelización]: las omisiones estratégicas que se cometen al construir un modelo casi siempre significan desaprovechar información real.» (Krugman, 1997: 69).
} 
cálculos aritméticos, en la programación del modelo en el ordenador o bien, finalmente, en la interpretación del modelo por el operador final inmerso en la actividad bursátil.

El riesgo de modelo aparece en los mercados financieros cada vez que un modelo de valoración de inversiones negociables deja de tomar en consideración algún factor relevante que influye sobre su cotización en los mercados reales, o bien, por ejemplo, asume de forma errónea que el movimiento de ciertas variables de carácter estocástico puede ser imitado con suficiente calidad usando cálculos deterministas, o piensa que la distribución empírica de los cambios de precios puede ser descrita mediante una distribución de frecuencias normalizada, con un rango de varianza altamente restringido. En otros casos, incluso aunque pueda considerarse que el modelo es «correcto en principio», o al menos no patentemente inconsistente desde el punto de vista de las restricciones que imponen los procedimientos de lógica formal, prueba matemática, contraste estadístico y diagnóstico probabilístico comúnmente admitidos por la comunidad académica y profesional en el campo de la modelización econométrica, los mercados pueden acabar estando en desacuerdo con sus resultados en el corto plazo. Puede suceder también que los parámetros numéricos empleados para resolver el modelo no hayan sido correctamente estimados, o bien que haya ocurrido un fallo durante el proceso de búsqueda heurística de su solución analítica, o que la aplicación informática que permite a una máquina computadora ejecutar el modelo contenga errores o «bugs», o bien que el trader que tiene instalado el programa en su ordenador lo use para ponerle precio a otros productos -0 al mismo producto pero en otros mercados- para los que el modelo no posee validez predictiva.

Como ha sido observado por numerosos practicantes en la materia, las premisas matemáticas y estadísticas básicas que se hayan incrustadas en el fondo de los modelos neoclásicos estándares de valoración de inversiones en equilibrio sufren tremendos problemas de consistencia cuando han de confrontarse con las estructuras y los procesos empíricos del mundo real de la negociación financiera y el management de riesgos empresariales. Así, mientras que los modelos de valoración en equilibrio asumen de forma típica que los mercados se componen de agentes atomizados que no pueden influir de forma sustancial sobre sus competidores ni tampoco manipular de forma individual las cotizaciones de los valores, el contagio imitativo y el comportamiento «en manada» (herd behaviour) son ubicuos en los mercados empíricos (Shiller, 2000, cap. 8) y algunos grandes inversores reputados ocasionalmente «mueven los mercados» (Soros, 1994). Los modelos financieros estándares suelen también dar por supuesto que la información financiera es un bien público simultánea y democráticamente accesible por todos los operadores relevantes, mientras que en la práctica se observan ritmos muy diferentes en el acceso a la información financiera en razón de la estructura organizacional de los mercados y sobre todo, como se vio más arriba, formas muy diferentes e incluso contrapuestas de analizar, esto es, de interpretar, dicha información. Más aún, la información teórica que incorporan diversos modelos de estimación de riesgos ha entrado recientemente, de la mano de la programación informática, en el dominio propietario, v.g. informacionalmente excluyente, 
de las patentes y los derechos de autor (Falloon, 1999) ${ }^{5}$. Las convenciones modelizadoras en vigor en este campo de investigación económica asumen también que los costes de transacción son mínimos y por tanto la liquidez de los mercados muy alta, aunque lo característico de los mercados reales sean más bien las crisis de liquidez (durante períodos prolongados nadie se presta a comprar/vender) acompañadas de «saltos» enormes en los precios y aun en las volatilidades de los valores, todo ello producto de la existencia de numerosas «fricciones» de carácter legal, organizacional o cultural que retardan, paralizan o desbaratan los tratos más seguros. Lo mismo vale para las otras dos hipótesis estándares del modelo neoclásico de mercados eficientes de capital, el principio de la igualdad crediticia y el de la neutralidad reguladora, que han de confrontar un mundo donde las restricciones crediticias y legales a la actividad financiera varían enormemente en razón del estatus social de los agentes económicos.

Esta controversia tan extremadamente «técnica» sobre la metodología más adecuada para definir, medir y gestionar los riesgos de modelo, inicialmente limitada al ámbito estrictamente académico y a la comunidad profesional más sofisticada, ha acabado convirtiéndose en pieza clave para la resolución de la feroz batalla negociadora que han venido librando a lo largo de la pasada década los portavoces de la industria global de derivados financieros y las agencias internacionales de regulación y supervisión financiera que velan por la correcta adecuación entre riesgos de inversión y reservas de capital en los mercados de derivados.

Probadamente impotentes para adaptar sus normas de inspección tradicionales al vertiginoso ritmo de evolución y sofisticación de las tecnologías y las operaciones de la industria de derivados, las autoridades monetarias y financieras internacionales, con el Comité de Supervisión Bancaria del Banco de Pagos Internacionales de Basilea a la cabeza, han acabado dando un giro copernicano a su modelo regulador. Enfrentados al fracaso continuo de los estándares supervisores de carácter administrativo, los «guardianes de la confianza impersonal» (Shapiro, 1987) en los mercados financieros internacionales tratan ahora de incorporar el mecanismo descentralizado de competencia tecnológica que permite mejorar continuamente los sistemas informáticos de gestión interna de riesgos empleados por las empresas privadas como pieza interna fundamental de sus nuevos sistemas de vigilancia administrativa (Dunbar, 1998).

La fijación de estándares públicos de modelización estadística del riesgo de modelización estadística del riesgo financiero se ha convertido así en el principal método de vigilancia y control público de la peligrosa «exuberancia irracional» de los mercados internacionales de derivados financieros sobre la que en su día advirtiera Alan Greenspan, el amado-temido Presidente del Banco de la Reserva Federal de EE.UU. A continuación examinamos en detalle los nuevos dispositivos reguladores a los que ha dado lugar la visibilidad creciente de los riesgos de modelo como factor esencial en la composición de los riesgos financieros de carácter global.

5 Incluso los datos brutos de cotización bursátil circulan ya en algunos casos, como el de los sistemas propietarios de negociación computerizada, como mercancías apropiables (Lee, 1998). 


\section{DE LA SUPERVISION BANCARIA A LA AUDITORÍA DE MODELOS}

A lo largo de la última década las autoridades nacionales e internacionales de supervisión financiera y la industria privada de derivados han negociado una serie de acuerdos sobre convenciones estándares de ingeniería financiera que pudieran servir para validar técnicamente y homologar administrativamente los modelos econométricos internos de medición y control de riesgos, a veces muy diferentes entre sí, que emplean los grandes bancos y fondos de inversión internacionales (Rhode, 1998).

Durante la década de los 80 la estructura institucional que regulaba el juego de la competencia en la industria internacional de servicios bancarios se vio azotada por una oleada de innovaciones productivas que modificó por completo la forma tradicional de llevar a cabo los negocios en este área económica. Como consecuencia de los nuevos tipos de productos y servicios de inversión que los bancos de negocios y las sociedades de bolsa hicieron poco a poco accesibles de forma sibilina a los bancos comerciales, a principios de los años 90 las operaciones bancarias denominadas «atípicas» (la compraventa de contratos bursátiles y las operaciones con derivados financieros) habían ganado ya un terreno considerable a las operaciones crediticias tradicionales (depósitos y préstamos) en las hojas de balance de los bancos comerciales y las cajas de ahorro.

Las autoridades reguladoras públicas nacionales e internacionales empezaron entonces a temer que la banca minorista pudiera verse fuertemente afectada por la aparición de un nuevo tipo emergente de riesgo financiero de poder devastador: el llamado riesgo de mercado. Bajo este concepto se esconde la posibilidad de que un movimiento adverso y coordinado en los precios que se forman en los mercados financieros internacionales pudiera ocasionar una cantidad tal de pérdidas de negociación bursátil en las cada vez más extensas carteras de instrumentos negociados en poder de los bancos comerciales que las reservas precautorias de capital que garantizan los depósitos de los ahorradores pudiesen llegar a verse afectadas, detonando así una espiral de quiebras y pánicos bancarios ${ }^{6}$.

La preocupación difusa de las autoridades por el riesgo de mercado se tradujo finalmente en una preocupación más concreta por la falta de adecuación de los sistemas tradicionales de reservas bancarias de seguridad para hacer frente a la frecuencia inusitada de las grandes fluctuaciones instantáneas de precios y los contagios masivos de tendencias a través de diferentes mercados de valores locales. El lugar donde estas preocupaciones fueron objeto de análisis y evaluación para la propuesta de medidas reguladoras de respuesta fue el Comité de Supervisión Bancaria del Banco de Pagos Internacionales de Basilea, conocido de forma abreviada como Comité de Basilea.

6 Para una perspectiva general de la emergencia histórica de la problemática del riesgo de mercado en el contexto de las prácticas de gestión de la industria financiera en el entorno global y los intentos de regulación y armonización supervisora en el ámbito nacional e internacional véase Torrero (1993, cap. 7) y Pérez Campanero (1995). 


\subsection{Las normas del Comité de Supervisión Bancaria de Basilea}

Durante las dos últimas décadas el Comité de Basilea del BIS ha adquirido el papel de principal foro de debate y negociación multilateral para la adopción de acuerdos internacionales en materia de estándares de supervisión de riesgos bancarios. En el seno de este último organismo se habría de gestar, a lo largo de la década de los 80 , la adopción del principal estándar regulador de la industria bancaria internacional, el Acuerdo de Capital de Basilea de 1988 (ACB), una regla de intervención que se había quedado ya anticuada incluso antes de comenzar a ser aplicada por muchos de sus signatarios. Las negociaciones del ACB se centraron principalmente en la regulación del llamado riesgo de crédito, esto es, el riesgo de impago por parte de los acreedores del banco, y no abordaron más que de forma programática el problema, aun incipiente en el momento de su adopción, del riesgo de mercado. El ACB prescribía solamente la aceptación por el conjunto de economías más desarrolladas de una serie de normas comunes de procedimiento externo, en realidad una metodología de modelización propia que las agencias reguladoras imponían a las instituciones reguladas que, por otra parte, aplicaban en su gestión diaria modelos internos de control de riesgos muy diferentes (Comité de Basilea, 1988). Por esta razón este modelo de regulación era conocido como el «enfoque estándar» 7 .

El caso es que, muy poco después de la formalización del ACB, el Comité de Basilea estaba planteándose ya muy seriamente la posibilidad de una modificación en el mismo para incluir bajo su manto un nuevo estándar de protección bancaria contra el riesgo de mercado. La nueva regulación propuesta debería afirmar un procedimiento simple, transparente y ampliamente consensuado, tanto con la industria como con los diferentes reguladores locales, para determinar la cantidad de reservas precautorias que deberían apartar de la circulación aquellos bancos en poder de enormes carteras diversificadas de acciones, bonos

7 Mediante la aplicación de un conjunto de criterios homologados de análisis crediticio, las distintas autoridades podían determinar, de un modo muy crudo pero normalizado, cual habría de ser el nivel adecuado de reservas inmovilizadas de capital que necesitaba apartar un banco en posesión de una cartera de créditos de composición determinada, cualquiera que fuera su jurisdicción local de referencia, para proteger a sus depositantes contra una oleada masiva de impagos de la deuda en su poder. La medida común de la solvencia bancaria se conoce como la Ratio de Cooke (en referencia a Peter Cooke, supervisor en jefe del Banco de Inglaterra, que ejercía entonces como presidente del Comité de Basilea, promotor del acuerdo). El Acuerdo de 1988 requería que las reservas de capital de los bancos alcanzasen al menos el $8 \%$ del total de los activos en poder del banco ponderados por su nivel de riesgo. Asimismo distinguía dos componentes o "tramos» de capital bancario: el Tramo 1 o de capital «nuclear» (emisiones de capital y reservas declaradas) y un Tramo 2 o de capital «suplementario» (valores perpetuos, reservas no declaradas, deuda subordinada con vencimiento superior a cinco años y participaciones redimibles a voluntad del emisor). Finalmente, el Acuerdo establecía una serie de ponderaciones en función del riesgo que servían para sopesar los requerimientos de capital en función de las distintas clases de activos. Así, por ejemplo, mientras que las letras del Tesoro de EE.UU. tenían asignada una ponderación de cero, los valores empresariales, incluyendo préstamos, bonos y acciones, recibían un peso del $100 \%$, lo que significaba que la posesión de estos últimos activos debería ser cubierta efectivamente con un 8\% del capital invertido en su compra (Swary y Topf. 1993: 450-456). 
y derivados para proteger a sus accionistas y a sus depositantes contra los vaivenes de las bolsas internacionales. El proceso de designación de una metodología universal para calcular este nuevo estrato superior de los requisitos de capital bancario se vio envuelto, a mediados de la década de los 90 , en una complicada controversia a la vez técnica, económica y política, que enfrentó principalmente a los defensores del modelo centralizado y externo de regulación mediante la imposición de un estándar de supervisión único, contra los abanderados de la auto-regulación en el interior de la industria por medio de la competición mercantil descentralizada y selectiva en la que tomarían parte la amplia variedad existente de modelos internos de supervisión empleados por los propios bancos. La controversia entró en su estadio defínitivo en el año 1997 cuando el Comité de Basilea, como colofón a una larga serie de papeles de trabajo e informes consultivos elaborados y consensuados en colaboración con varias otras agencias internacionales (principalmente IOSCO -International Organisation of Securities Comissions) y organizaciones privadas (como ISDA, International Swaps and Derivatives Association), emitió por fin una nueva reglamentación que permitía a los bancos usar su propio modelo interno de control de riesgos y sus propios sistemas computerizados de gestión para determinar de forma idiosincrásica la cantidad apropiada de reservas de capital (Comité de Basilea, 1996a: 38-50).

Por oposición al anterior enfoque estándar de la vigilancia administrativa del riesgo de crédito, el nuevo régimen regulador de las reservas de capital contra el riesgo de mercado es conocido como el «enfoque de modelos internos». En su mayor parte, los sistemas internos de control de riesgos empleados por los bancos giran en torno a una clase característica de modelos econométricos de valoración de activos en equilibrio conocidos como modelos de «valor en riesgo» (en inglés «Value-at-Risk» o VaR models). Los modelos VaR son en realidad una generalización de la teoría clásica de la formación de carteras óptimamente diversificadas con la que se pretende atacar el siguiente problema práctico: cómo determinar la cantidad máxima de pérdidas financieras, esperada con una probabilidad significante y para un nivel de confianza estadístico dado, que podría llegar a sufrir una cartera de valores apropiadamente diversificada a lo largo de un periodo temporal dado, como consecuencia de un movimiento adverso y pronunciado en los precios financieros coordinado a través de diferentes tipos de instrumentos, plazos y mercados.

El documento de la Enmienda al Acuerdo de Basilea de 1996 codifica el conjunto estándar de principios teóricos de base y criterios estadísticos «generalmente admitidos» por los que se habrán de guiar en lo sucesivo los bancos privados para construir sus modelos internos de valor en riesgo de tal modo que puedan ser homologados inicialmente e inspeccionados con posterioridad de forma periódica por los supervisores nacionales. Expondremos ahora las líneas generales de este marco metodológico estándar.

\subsection{El diseño econométrico de los modelos de «valor en riesgo» (VaR)}

El valor en riesgo se define técnicamente como una medida probabilística, una expectativa o esperanza matemática de pérdidas, esto es, la probabilidad 
matemática asociada a la ocurrencia media de un fenómeno (calculada sobre la base de la distribución de frecuencias de una muestra de movimientos de precios ocurridos durante un periodo dado de observaciones históricas) multiplicada por el valor económico de ese fenómeno ${ }^{8}$. La información que arrojan los modelos VaR consiste por tanto en una cifra de pérdidas pecuniarias máximas (pe. 500.000 euros) asociada a una probabilidad numérica de ocurrencia (1\%), un nivel de confianza estadístico (99\%) y un plazo temporal ( 1 día) (para el caso: solamente 1 de cada 100 días, la cartera de valores del banco podría llegar sufrir pérdidas máximas de hasta 500.000 euros, y ello con un margen de error de \pm 1 días). La implicación final del cálculo VaR es informar sobre la probabilidad de que una empresa financiera, un banco por ejemplo, sufra pérdidas económicas de gran magnitud en sus posiciones financieras abiertas en el mercado a causa de una variación súbita en los precios de mercado de los distintos activos.

El cálculo del valor en riesgo de una cartera de inversiones se plantea en la práctica como un problema de supercomputación matemática: la estimación de un conjunto de parámetros estadísticos estables en el interior de una matriz gigantesca de covarianzas estadísticas entre movimientos de precios bursátiles. Se trata de reducir a una única cifra-resumen una enorme tabla de doble entrada que contiene una muestra histórica de (la infinita variedad posible de) grados de sincronización temporal entre (a) las desviaciones medias de la rentabilidad esperada de un activo financiero individual, y (b) las de todos y cada uno de los miles de activos alternativos que coexisten con él en el mercado. Este cálculo no está exento de controversia, pues el significado del numerito en cuestión depende una red subterránea de supuestos y premisas teóricas de base susceptibles de variación $\mathrm{y}$, por tanto, de crítica.

El procedimiento más empleado para el cálculo de cifras $\mathrm{VaR}$ es el llamado método histórico, que consta de dos pasos. En primer lugar es necesario disponer de una amplia base de datos históricos de carácter numérico, una sección muestral del comportamiento a largo plazo de los mercados que permita estimar una serie de tendencias estadísticas robustas en relación con (a) los precios de mercado de un amplio espectro de instrumentos de inversión (las cotizaciones al cierre de cada sesión diaria de las acciones, los índices bursátiles, los bonos de deuda. los contratos de futuro, etc.), (b) sus volatilidades, esto es, las desviaciones promedio de esas cotizaciones respecto de su nivel medio histórico, y (c) sus correlaciones, el grado de interacción entre el movimiento a largo plazo de cada activo considerado individualmente y el de todos y cada uno de los demás valores que están relacionados con él. Estos tres tipos de estadísticos muestrales (cotizaciones medias, volatilidades y correlaciones) constituyen las variables objeto de tratamiento analítico dentro de un modelo econométrico neoclásico generalizado, un modelo de valoración competitiva de activos financieros que obedece al consabido principio del análisis media-varianza de la teoría financiera neoclásica (la

\footnotetext{
${ }^{8}$ Sobre la metodología econométrica y los usos financieros de las técnicas de modelización VaR véase Jorion (1997a) y Duffie y Pan (1997). Para una crítica general del diseño econométrico de este tipo de modelos, así como de su utilidad para la gestión de riesgos financieros en el mundo real, véase Taleb (1997a).
} 
diversificación óptima de riesgos definida como la minimización de la varianza agregada de una cartera de valores para cualquier nivel considerado de rentabilidad esperada) ${ }^{9}$.

La Enmienda de 1996 al Acuerdo de Capital de Basilea establecía una serie de requisitos mínimos generales a aplicar por las autoridades supervisoras de ámbito nacional para aprobar el uso de modelos internos de medición de riesgo por parte de las corporaciones bancarias bajo su jurisdicción. En general las autoridades supervisoras deberían certificar (a) la validez conceptual y la integridad técnica en la implementación del modelo bancario; (b) la disponibilidad en número suficiente, por parte del banco, de personal cualificado en el uso de modelos econométricos sofisticados, no sólo en el área de negociación sino también en las divisiones de control de riesgos, auditoría y oficina de respaldo; (c) que el modelo econométrico del banco posea, a juicio de la autoridad supervisora, una trayectoria de resultados razonablemente ajustados en sus medidas del riesgo; y (d) que el propio banco lleve a cabo de manera regular auditorías internas de la calidad de su modelo mediante la aplicación de "pruebas de esfuerzo» (stress testing) normalizadas.

En cualquier caso, la conciencia emergente en el seno del Comité sobre los nuevos tipos de riesgos a los que abre la puerta el régimen regulador basado en los modelos internos -en particular el riesgo de modelo-, quedaba también reflejada en el texto final de la Enmienda al Acuerdo de Capital, con la imposición, como mecanismo de protección, de una serie de factores correctores que modifican al alza los resultados obtenidos por el modelo interno ${ }^{10}$.

${ }^{9}$ Un planteamiento diferente del problema del valor en riesgo no parte de la teoría de carteras, sino de la teoría matemática de valoración de opciones. En este caso, las variables fundamentales del modelo no son las correlaciones o las volatilidades históricas sino los factores fundamentales de riesgo que permite derivar el modelo de Black-Scholes: delta, gamma, vega, rho, etc., lo que en la terminología profesional se conocen como las «griegas». En este marco alternativo de análisis cada producto financiero particular se descompone o "granulariza» en forma de factores básicos de riesgo: «riesgo delta», «riesgo gamma», etc. Luego, usando técnicas de correlación, se agregan enormes cantidades de estos pequeños gránulos o átomos de riesgo y se obtiene una cifra única final que mide el rendimiento ajustado al riesgo de todo el capital de inversión gestionado por la empresa en los mercados. Otras dos variantes que se emplean como complemento a los análisis basados en el cálculo de volatilidades históricas y factores fundamentales de riesgo son los métodos de simulación informática (métodos de Monte Carlo) que calculan parámetros de correlación estadística a partir del análisis de gran número de muestras artificiales de datos pertenecientes a diferentes tipos de distribuciones aleatorias generadas por ordenador. Se usan también, finalmente, diversos métodos complementarios para evaluar la consistencia de los modelos econométricos de control de riesgos en presencia de condiciones de mercado «anómalas" y circunstancias históricas «muy improbables». Entre estos últimos destacan el llamado «análisis de escenarios», en el que se emplea un simulador informático de situaciones de mercado alternativas con gran número de grados de libertad para probar la sostenibilidad de las medidas teóricas de riesgo ante eventualidades histórico-económicas complejas, y las «pruebas de resistencia al esfuerzo» (stress testing) que permiten someter a las carteras de inversiones óptimamente diversificadas a condiciones de mercado artificialmente desordenadas que simulan situaciones pánicas asociadas con valores probabilísticos extremos (Dunbar, 1999).

${ }^{10}$ Así, sobre la cifra final arrojada por los modelos internos de valor en riesgo deberá aplicarse un factor multiplicador de ajuste (con un valor mínimo preestablecido de 3 ), y en caso de que una inspección posterior revele la existencia de fallos en el modelo interno, deberá añadirse un segundo factor de elevación con un valor de entre 0 y 1 . La sobredotación de reservas de 
Finalmente, y más allá de este eventual mecanismo corrector de carácter general, la enmienda al Acuerdo de Capital de Basilea sobre el uso de modelos internos de control de riesgo que entró en vigor en 1997 iba acompañada de un documento supervisor complementario que establecía una serie de orientaciones y criterios generales a poner en práctica por los supervisores bancarios locales para conducir sobre el terreno procedimientos detallados de auditoría externa de la calidad de los modelos internos de valor en riesgo de los bancos.

El documento en cuestión donde se exponen los fundamentos y la operativa de estos controles de calidad, lleva por título Marco supervisor para el uso del «backtesting» en conjunción con la metodología de modelos internos para determinar los requisitos de capital bancario en razón del riesgo de mercado, y es un pequeño informe de 12 páginas, elaborado por una Comisión delegada para el estudio de los Modelos (Models Task Force), hecho público en enero de 1996 por el Comité de Basilea simultáneamente con la publicación del texto general de la Enmienda al Acuerdo de capital (Comité de Basilea, 1996b). El propósito de este documento complementario era dotar al nuevo sistema de vigilancia administrativa «a distancia» de incentivos de cumplimiento regulador que asegurasen en cierta medida al público de que, para procurar que sus modelos internos de control de riesgos siguiesen en el futuro siendo aceptados por las autoridades como «aliados reguladores», los bancos habrían de adoptar las (costosas) medidas oportunas para poner al día y mejorar la validez, precisión y eficiencia de sus modelos internos de medición de riesgos.

\subsection{Backtesting: auditando la calidad de los modelos de control de riesgos}

El documento en cuestión detalla cómo deben llevarse a cabo una serie de tests normalizados de «contraprueba» o backtesting para verificar estadísticamente, a la manera de los controles de calidad industrial, el desempeño de los modelos internos bancarios en relación con los riesgos reales determinados por el mercado. Para garantizar que los bancos privados dedicarán los esfuerzos y recursos necesarios para actualizar y mejorar de forma continua sus modelos internos de control de riesgos, el Comité dispone que las diferentes autoridades nacionales de supervisión bancaria -en nuestro país la Inspección del Banco de España- apliquen de forma periódica un mismo procedimiento estadístico de auditoría de sistemas de control interno. Este procedimiento de meta-vigilancia de la información estadística que maneja la gerencia interna de los bancos tiene como propósito garantizar el cumplimiento de unos requisitos mínimos de eficiencia predictiva por parte de las cifras teóricas de valor en riesgo que el consejo de administración del banco utiliza para determinar autónomamente el nivel óptimo de reservas del mismo.

seguridad a la que se tiende de este modo hace las veces de una auténtica póliza de seguros contra el riesgo de modelo. 
Tal como los define el documento del Comité, los programas de backtesting consisten en una comparación periódica de las medidas teóricas de valor en riesgo calculadas por el modelo interno del banco para un horizonte temporal de un día respecto de las cifras de beneficios y pérdidas diarias realmente observadas, esto es, los «resultados de negociación» efectivamente producidos al final de cada sesión diaria (Comité de Basilea, 1996b: 2). Por construcción, como hemos visto, las medidas teóricas de valor en riesgo pretenden subsumir la práctica totalidad de los resultados de negociación esperables al final de cada día, dejando solamente fuera de cobertura una pequeña fracción de los mismos, que viene determinada por el intervalo de confianza escogido para calibrar el modelo de valor en riesgo. A este respecto el Comité establece que el porcentaje de resultados de negociación que deben cubrir las medidas teóricas del riesgo que arroja el modelo del banco debe ser «consistente» con un nivel de confianza del $99 \%$.

Para evaluar el grado de efectividad del modelo de medición de riesgos del banco lo que se hace simplemente es (1) contar primero el número de «excepciones» que produce el modelo, esto es, cuántas veces los resultados de negociación (pérdidas o ganancias reales) efectivamente realizados al final de cada sesión diaria caen fuera de la expectativa teórica de valor en riesgo que proporciona el modelo del banco, y (2) determinar luego si el número de excepciones es o no consistente con el nivel de cobertura obligado del $99 \%$. Para hacer compatible una cierta regularidad de los exámenes supervisores de los modelos internos con un carácter mínimamente representativo, en el sentido estadístico, de los datos que sirven de base para la evaluación, el Comité recomienda llevar a cabo estos exámenes con periodicidad cuatrimestral, debiendo usar los evaluadores los datos de negociación de los últimos 12 meses, lo cual supone contar con un tamaño muestral de unas 250 observaciones (250 días de negocio). Así, por ejemplo, para una muestra de 250 días de negociación, una medida de valor en riesgo diario calibrada a un nivel de confianza del $99 \%$ debería cubrir, en promedio, 248 de los 250 resultados de negociación observados, dejando sólo dos excepciones fuera de sus cálculos.

Si el modelo produjese, pongamos, 125 excepciones, es decir, se contasen en una muestra de 250 días 125 resultados no cubiertos por la expectativa teórica del riesgo que maneja el banco ex ante, «sería claro» a ojos del supervisor que hay algo en sus supuestos de base o en sus métodos de cálculo que no funciona, debiendo compensarse la debilidad predictiva del modelo con una elevación proporcional en el factor multiplicador de sus reservas de capital que haga regresar al modelo al nivel de confianza del $99 \%$.

Pero el auténtico problema con el que se enfrenta el arte de la vigilancia bancaria en el domino de la auditoría de calidad de los modelos de riesgo de mercado estriba en saber cómo interpretar un resultado del backtesting que arrojase por ejemplo, para este mismo caso, un número de excepciones sólo ligeramente superior a 2, como 467 , cifras que, desde un punto de vista puramente probabilístico, no proporcionan ninguna señal concluyente sobre la auténtica solidez predictiva del modelo. Para resolver esta ambigüedad fundamental de los resultados del backtesting, el Comité establece entonces un segundo tipo de criterios numéricos con los que demarcar de forma clara las diferentes zonas de 
«seguridad» (zona verde), «precaución» (amarilla) y «peligro» (roja) en las que caen los diferentes modelos internos como consecuencia del grado de «fortaleza estadística» de la señal generada por el backtesting de sus resultados. La zona verde en primer lugar abarca todos los resultados del backtesting -entre 0 y 4 excepciones para una muestra de 250 observaciones- que, desde un punto de vista probabilístico estándar, no sugieren ninguna duda sobre la validez predictiva del modelo y por tanto cuya lectura no produce respuesta supervisora alguna en el sentido de una elevación del nivel de capitalización. Dentro de la zona amarilla caen los resultados que producen dudas no concluyentes sobre la efectividad del modelo -entre 5 y 9 excepciones- y cuya lectura podría ir acompanada de elevaciones de entre 0.40 y 0.85 puntos en el factor multiplicador de la base de capital. Finalmente en la zona roja entran todos los resultados iguales o superiores a 10 excepciones, cuya medida correspondiente es la elevación en un punto del factor multiplicador.

\subsection{El policía como metodólogo}

La entrada en vigor, a finales de 1997, de la Enmienda aprobada en 1996 al Acuerdo de Capital de Basilea firmado en 1988 supuso la aceptación de los modelos internos de control de riesgos empleados por los propios bancos como herramientas legítimas de control público. Esta nueva directriz define un verdadero cambio de paradigma supervisor en el ámbito de la regulación pública de los riesgos bancarios. Se ha pasado de un modelo inspector directo (para el riesgo de crédito) basado en la imposición externa de un único conjunto normalizado de criterios genéricos para la determinación del nivel de reservas de capital preventivo, a otro modelo de supervisión de naturaleza indirecta (el del riesgo de mercado) basado en la realización de pruebas mediatas de consistencia y validación metodológica sobre diferentes modelos econométricos de control interno de riesgos, con objeto de verificar el cumplimiento de un conjunto de requisitos mínimos de homologación técnica.

Así pues, en el momento actual, algunas de entre las más significativas tareas de supervisión bancaria tradicionalmente asignadas a las agencias de regulación pública están siendo llevadas a cabo de una manera asombrosamente indirecta a través de procedimientos de auditoría de modelos y sistemas de control. En este nuevo régimen regulador, los niveles efectivos de protección bancaria sólo pueden ser adivinados por las autoridades públicas mediante un proceso de auditoría virtual que trata de evaluar la consistencia empírica, la solidez computacional y la flexibilidad organizacional de los modelos internos de gestión empresarial de riesgos de inversión empleados por los bancos.

Siendo la estadounidense la industria financiera más poderosa del planeta, su sistema de vigilancia bancaria tenía por fuerza que ser uno los más complejos. Dicho sistema está compuesto por tres oficinas federales: la Office of the Comptroller of the Currency (OCC) (Oficina del Controlador de la Moneda), la Federal Deposit Insurance Corporation (FDIC) (Corporación Federal de Aseguramiento de Depósitos) y el Sistema de la Reserva Federal (Swary y 
Topf, 1993: 333-334). Dependiente del poderoso Departamento del Tesoro, la OCC es tal vez la pieza central del complejo entramado de agencias de supervisión bancaria de ámbito federal. Dentro del organigrama de cuerpos de gestión e inspección de la OCC, existe una división específica dentro de la unidad de análisis de riesgos bancarios, conocida como Risk Analysis Division (RAD). Esta división es la encargada de llevar a cabo las pruebas de backtesting para comprobar que los cálculos de riesgo con los que trabajan las entidades bancarias cumplen con los requisitos mínimos de validez teórica, adecuación empírica y solidez práctica establecidos por la OCC en cumplimiento de la normativa del Comité de Basilea.

Del mismo modo que los principios de codificación del procedimiento de backtesting para el control de calidad (v.g. fiabilidad estadística) de los modelos de valor en riesgo llevada a cabo por el Comité de Basilea confieren a la misión pública desempeñada por esta agencia internacional el aire de un verdadero «prestamista epistemológico de último recurso» para el expertizaje técnico de los ingenieros financieros, el personal de este otro negociado público se ve a sí mismo, más que como un conjunto de burócratas convencionales, como el equivalente funcional de los revisores de las publicaciones científicas en el ámbito de la ingeniería financiera aplicada.

«El personal de la RAD mantiene una entrevista cara a cara con los modelizadores del banco para recolectar información y documentación técnica para los examinadores. «Estamos aquí para asegurar que tenemos a alguien sentado a la mesa, inmerso en el proceso de supervisión, que comprende el lenguaje en el que hablan los modelizadores de los bancos», dice [Jeffrey] Brown [director de la RAD] [...] Según Brown, para asegurarse de que existe algún estándar común [entre los modelos internos de los diferentes bancos] la RAD solicita a cada banco individual que lleve a cabo una serie de pruebas formales para validar la solidez de su propio modelo. Como parte de cualquier examen bancario, el personal de la RAD busca evidencia documental de que este proceso de validación interna ha sido llevado a cabo, y asimismo evalúa lo razonable de las premisas teóricas en las que se basan los modelos. La tercera parte del examen consiste en el contraste entre modelos [benchmarking], para verificar que el banco ha comparado efectivamente los resultados ofrecidos por su modelo particular con los resultados arrojados por otros modelos estándares... El paso final en este proceso de revisión es el más crítico. Implica contrastar los resultados de un modelo con los datos reales del mercado cuando dichos datos se encuentran disponibles. «Estos procedimientos son todos estándares en la ciencia social que llamamos economía o finanzas, y nosotros queremos ver evidencia palpable de que cada banco los aplica.» (Falloon, 1998: 25).

¿Puede alguien distinguir si se está describiendo un ejercicio exhaustivo y sofisticado de evaluación de una metodología científica o si se trata tan sólo de una investigación administrativa rutinaria? ¿Podría tratarse de ambas cosas?

Ciertamente, las normas procedimentales del Comité de Basilea y la OCC para la validación pública del uso de modelos econométricos aplicados a la gestión bancaria están bastante alejadas de la frontera de conocimiento que definen 
los trabajos de investigación publicados por las principales revistas académicas en el campo de la teoría y la metodología de la modelización econométrica aplicada (Econometric Theory, Journal of Econometrics, etc.) Sin embargo para los examinadores públicos es mucho más cómodo, vale decir, mucho más económico, usar la misma regla de juicio para todos, sin tener en cuenta las (enormes) diferencias existentes entre los modelos internos al nivel de su sofisticación metodológica y tecnológica. Esto es, aplicar un repertorio estandarizado de pruebas meta-estadísticas «claras», «sencillas» y «rápidas», aunque «limitadas»e «imperfectas», para determinar grosso modo la calidad científica de los miles de millones de estimaciones estadísticas del riesgo financiero que llevan a cabo cientos de corporaciones financieras.

Pero si se toman demasiado al pie de la letra, los umbrales convencionales que delimitan las fronteras entre las tres zonas, pueden inducir a los supervisores a cometer dos tipos de error estadístico en la interpretación de los resultados del backtesting: clasificar como defectuoso un modelo que realmente es válido (error de tipo 1), o admitir como correcto un modelo que realmente no es válido (error de tipo 2). En este sentido el documento complementario del Comité se acompana con un conjunto de cálculos numéricos de las probabilidades teóricas que existen de obtener un número cualquiera de excepciones para una muestra de 250 observaciones independientes para distintos niveles de cobertura del modelo $(99 \%, 98 \%, 97 \%, 96 \%$ y $95 \%)$. Estos cálculos muestran que existe una alta probabilidad de rechazar de forma equivocada un modelo válido cuando, para un nivel confianza del $99 \%$, se escoge un número demasiado bajo de excepciones como umbral de rechazo (ej. si el umbral se fija en una excepción, modelos completamente válidos serán rechazados por los evaluadores el $91.9 \%$ de las veces).

Por supuesto, si se eleva el umbral del número máximo de excepciones que puede producir un modelo para ser considerado válido, la probabilidad de cometer un error de este tipo disminuye, pero aumenta en cambio la probabilidad de cometer un error de signo contrario: para un umbral de rechazo fijado en siete excepciones o más, los cálculos del Comité indican que un modelo que sólo ofrezca una cobertura del $97 \%$ (un modelo no válido por definición) será aceptado erróneamente el $37.5 \%$ de las veces. Este tipo de problemas lo plantean sobre todo aquellos resultados del backtesting incluidos dentro de la zona amarilla, puesto que los cálculos estadísticos estándares demuestran que las probabilidades de arrojar resultados de entre 5 y 9 excepciones son muy próximas en el caso de modelos correctos (cobertura del 99\%) e incorrectos (cobertura del 98 o el $97 \%$ ).

Para atacar el problema de la ambigüedad de las señales que arrojan las pruebas de backtesting, las directrices supervisoras emanadas del Comité de Basilea establecen que, en aquellos casos en los que la información cuantitativa estandarizada producida por la prueba de backtesting no proporcione al examinador público sino evidencias confusas en relación con el grado real de eficiencia predictiva del modelo interno de control de riesgos, el agente de la autoridad supervisora podrá requerir al banco para que, con objeto de respaldar la fiabilidad de su modelo, aporte un conjunto de información complementaria de carácter cualitativo tanto sobre los detalles teóricos de la arquitectura conceptual del modelo 
objeto de supervisión, como sobre el carácter «especial» (extremo, históricamente improbable o irreproducible) de los resultados de negociación que no fueron predichos por el mismo. La carga de la prueba en estas situaciones, se afirma en el informe del Comité, no debe «recaer sobre el supervisor, para probar que existe un problema con el modelo, sino sobre el banco objeto de supervisión, para probar que su modelo es fundamentalmente sólido.» (Comité de Basilea, 1996b: 8).

\section{TIPOS DE ALEATORIEDAD, ERRORES E IMPRUDENCIAS}

Los contra-expertos, reclutados de entre los departamentos académicos y las firmas de consultoría estratégica de mayor prestigio, que asesoran a los grandes bancos en materia de certificación de modelos de control de riesgos, producen una enorme cantidad de material documental para intentar justificar mediante argumentos técnicos «plausibles» que las excepciones detectadas por el backtesting, e incluso las más flagrantes de entre ellas, no implican en modo alguno la existencia de responsabilidad por parte de los desarrolladores del modelo matemático.

El propio informe del Comité de Basilea sobre las pruebas de backtesting avanza la forma argumentativa canónica que habrá de adoptar este modelo general de justificación pública de las excepciones predictivas producidas por los modelos de control del valor en riesgo:

«Incluso un modelo exacto no es esperable que cubra el $100 \%$ de los resultados de negociación. Algunas excepciones serán seguramente producto del $1 \%$ de eventos aleatorios que el modelo no espera cubrir. En otros casos, el comportamiento de los mercados puede cambiar de tal modo que estimaciones previas de las volatilidades y las correlaciones se convierten en menos apropiadas. Ningún modelo de valor en riesgo será inmune a este tipo de problema que es inherente a la confianza depositada en el comportamiento pasado del mercado como medio para aprehender el riesgo de movimientos futuros del mercado" (Comité de Basilea, 1996b: 10).

En el caso de que un banco determinado hubiese establecido un nivel de reservas insuficiente para asegurar completamente a sus acreedores ante un gigantesco movimiento adverso de los precios financieros en todos los mercados mundiales, y sin embargo un movimiento tal llegase a producirse efectivamente con posterioridad-como consecuencia de, pongamos, una crisis social abrupta en un país extranjero, como una guerra civil o una ruptura constitucional- provocando la quiebra financiera de la corporación y desencadenando la consiguiente investigación administrativa, los defensores del modelo VaR del banco presentarían a las autoridades supervisoras un informe histórico-sociológico que probase que el suceso en cuestión constituía una de esos acontecimientos económicos absolutamente excepcionales, una de esas «tormentas bursátiles perfectas» que la teoría econométrica estándar de las fluctuaciones financieras confina dentro del capítu- 
lo especial del $1 \%$ de sucesos aleatorios extremos que son completamente impredecibles e inasegurables por definición ${ }^{11}$.

Pero si ese mismo error hubiese tenido como suceso económico de referencia la ocurrencia de un cambio adverso en los precios financieros que se considerase estrictamente causado por las así llamadas «fuerzas endógenas» del mercado, del tipo de los ciclos estacionarios recurrentes que se supone gobiernan los niveles de demanda agregada de bienes de consumo o las tendencias estocásticas estables que se supone animan el movimiento de las tasas de crecimiento del PIB, la eventual bancarrota de una corporación financiera insuficientemente protegida por su nivel de reservas contra el evento en cuestión, sería en este caso más difícilmente justificable como consecuencia de emplear un modelo de control de riesgos impotente para aprehender un ambiente de «incertidumbre mercantil extrema». Los examinadores públicos sospecharían sin duda aquí la realización previa de determinadas operaciones de «maquillaje econométrico» que lograron que la prueba del backtesting transmutase un modelo predictivo de baja calidad en un modelo consistente de control de riesgos que cumplía con todos los requisitos supervisores en materia de fiabilidad tecnológica.

Dentro del mundo de la academia y la profesión financiera han surgido recientemente un conjunto de voces críticas que ponen en cuestión la separación radical entre lo normal y lo excepcional que impone este régimen característico de argumentación pública. En efecto, desde mediados de la década de los 90 , la controversia académica sobre la gestión y los usos en materia supervisora de los modelos econométricos de valor en riesgo ha producido ya un largo repertorio de justificaciones y críticas metodológicas, teóricas y epistemológicas para tipos muy diversos, y aún contrapuestos, de práctica econométrica (Taleb, 1997a, 1997b; Jorion, 1997b). De entre los argumentos críticos más peliagudos esgrimidos en el contexto de esta dialéctica del supervisor y el supervisado, destaca sin duda la acusación de «arbitrariedad metodológica» lanzada por los expertos que respaldan la solidez de los modelos internos bancarios contra los intervalos de confianza estadística impuestos por los examinadores públicos para evaluar los resultados del backtesting de los modelos. La crítica de los intervalos de confianza implica en realidad la apuesta por la existencia de un tipo de incertidumbre económica radical, de carácter no mensurable y, por tanto, no computable, como fuente última de todo fallo concebible en la fiabilidad econométrica y computacional de los modelos de control de riesgos financieros.

Recordemos que la elección de un intervalo de confianza del $99 \%$ implica que solamente en 1 de cada 100 sesiones de negociación las pérdidas podrán exceder la cifra VaR computado por el modelo. Pero el intervalo de confianza es en realidad un artefacto producido por la adscripción a una premisa teórica más fundamental (y más disputable), como es la elección de una distribución de probabilidad característica. En el dominio de la econometría financiera neoclásica,

1 Lejos de ser un ejemplo hipotético, este es, grosso modo, el esquema argumental la controversia pública desatada tras la quiebra del fondo de cobertura Long-Term Capital Management, con la suspensión de pagos de la deuda soberana de Rusia en el papel de «suceso extremo» (Dunbar, 2000: xiii). 
la confianza estadística no es sino el vástago de la normalidad probabilística, y cuando la normalidad o gaussianidad se rechaza como una representación algorítmica adecuada de la distribución empírica de frecuencias de los cambios de precios, queda rechazada también la confianza estadística «normal» como un instrumento adecuado para evaluar la fiabilidad econométrica de los modelos VaR.

Siguiendo el camino trazado inicialmente por las mismas corporaciones financieras a las que auditaban, los supervisores públicos se adhirieron de forma incondicional al cómodo asidero burocrático que proporciona esta concepción «benigna» del azar económico. Pero, como ha venido siendo denunciado desde hace más de cuatro décadas por los críticos más incisivos de la metodología econométrica de los modelos neoclásicos de mercados eficientes de capital, existe una brecha flagrante entre estos modelos fácilmente manejables de aleatoriedad «benigna», asumidos de forma explícita por la gran mayoría de los valedores académicos y los practicantes profesionales (los ingenieros financieros) de la economía financiera neoclásica (Walter, 1996), y el tipo de aleatoriedad «salvaje» (Mandelbrot, 1963), que sería más bien característico de todo proceso auténticamente histórico, en el que los parámetros que limitan el margen de maniobra de la acción social no pueden ser fijados a priori de forma externa por observador, analista o experto alguno.

«La de aleatoriedad es una idea intrínsecamente difícil puesto que parece chocar con hechos e intuiciones muy poderosas. Si en física choca con la idea de determinismo, en finanzas choca con las idea de causalidad clara, racionalidad económica y tal vez libre albedrío... En física el problema parece estar mitigado por el hecho de que los átomos de un gas no se conocen de forma individual, mientras que en finanzas el problema se agrava por exactamente la razón opuesta. Peor aún, en finanzas es difícil desenredar los papeles del observador y del participante activo.» (Mandelbrot, 1997: 15).

Mientras que los defensores del azar benigno gaussiano cualifican los movimientos extremos de precios como fenómenos económicos que sólo pueden ser producidos por dos tipos de causas, bien aquellas de carácter determinista, bien aquéllas que operan a muy largo plazo, definiéndolos por tanto como sucesos altamente improbables a cualquier escala espacial o temporal, para los defensores del azar salvaje los grandes movimientos de precios pueden ser causados por factores cuyo valor no es determinable dentro del modelo teórico empleado y que a la vez pueden ser observados en la escala micro de las dinámicas económicas de corto plazo (Izquierdo, 1998: 69-75). Por ello son siempre, en cierto sentido, demasiado probables en relación con los límites impuestos por las convenciones modelizadoras imperantes en el mundo de la ingeniería financiera ${ }^{12}$.

12 «De acuerdo con la teoría neoclásica de selección de carteras eficientes, la probabilidad de que ocurra una fluctuación en los precios de tamaño superior al de 10 desviaciones estándar sería de unas pocas millonésimas de una millonésima de millonésima de millonésima... Pero de hecho lo que se observa en la práctica es que este tipo de fluctuaciones de gran tamaño ocurren de forma regular en los mercados - tan frecuentemente como cada mes- y que su probabilidad alcanza unas cuantas centésimas.» (Mandelbrot, 1999:70.) 
Sin duda alguna, la silenciosa disolución de esa amenaza cuasi-metafísica que es la «debacle económica imprevisible» que se opera mediante la aceptación acrítica, como estructura argumentativa de validez general, de esa maquinaría característica de justificación tecno-política que es la inducción probabilística guassiana, mediante la que se aísla perfectamente la presencia de mecanismos económicos estables de la de procesos históricos irrepetibles, no es ya un expediente administrativo tan inconsciente como solía. Este confortable principio de visión y división administrativa del mundo, el axioma guassiano que establece que todo fenómeno verdaderamente aleatorio sólo puede ser entendido como fenómeno microscópico y por tanto despreciable (los pequeños accidentes no cambian el curso de la historia), está ahora en entredicho como criterio general de enjuiciamiento de las decisiones corporativas en los mercados de derivados financieros. Tanto por la pura brutalidad de los acontecimientos económicos como por la necesidad estratégica de adaptarse a los cambios de la normativa administrativa en materia de supervisión financiera, los profesionales de las finanzas han sido conducidos a reflexionar sobre los fundamentos teóricos más oscuros y en teoría menos disputables que respaldan la 'base de conocimientos' incorporada en sus sistemas expertos de gestión de riesgos. Esto es, el conjunto de convenciones que sostienen el mito de la fiabilidad tecnológica en el mundo de la econometría financiera aplicada. De hecho, hasta los altos ejecutivos de las grandes corporaciones financieras han comenzado ya a expresar en público serias dudas sobre la veracidad del dogma neoclásico de la separación entre aspectos deterministas y estocásticos de la dinámica económica ${ }^{13}$.

La ironía de todo esto es que el punto fuerte de la crítica racional (científica) de las prácticas establecidas de gestión privada y supervisión pública del riesgo financiero debe en este caso ser completamente inaceptable para los supervisores públicos. Aceptar el retrato estadístico de la «aleatoriedad salvaje» mandelbrotiana como una descripción científicamente más razonable de la forma espectral típica que adopta el despliegue del riesgo financiero en el mundo real implicaría de hecho rechazar que los cuerpos de supervisión pública que velan por la salud de la industria financiera tengan razón alguna para seguir existiendo.

«Mandelbrot permanece en la periferia de la teoría financiera, tanto por la inconveniencia que para los analistas supone el aceptar sus argumentos, como

13 Como lo acredita el siguiente testimonio de Robert Gummerlock, el director ejecutivo, durante buena parte de la década de los 90 de la Swiss Bank Corporation, uno de los más importantes dealers internacionales de derivados financieros: «En el mundo de distribuciones normales que nos pintan por los manuales académicos, un movimiento de 10 desviaciones estándares es un suceso con una probabilidad que va más allá de uno entre un millón. En los mercados financieros sabemos que esto no es así; de modo que tenemos que decidir con qué frecuencia ocurrirá. Lo problemático con las distribuciones de «cola gorda» es que fomentan el vínculo entre los eventos ordinarios y los extraordinarios. Bajo una distribución estrictamente normal, los eventos extraordinarios están estrictamente gobernados por las probabilidades, y la desviación estándar ejerce su vigilancia. Con distribuciones de cola gorda, los extremos pueden ocurrir con una frecuencia alocada y ningún tipo de análisis de desviación estándar puede proporcionar información sobre ellos.» (citado en Chew, 1994, 64.) 
por el natural deseo humano de esperar que las fluctuaciones permanezcan confinadas entre límites familiares.» (Bernstein, 1992: 132).

Efectivamente, el establecimiento de requisitos mínimos para la reservas bancarias de capital sólo tiene sentido en un mundo donde el riesgo financiero es estadísticamente determinista, es decir, donde podemos asignar probabilidades estables de ocurrencia a diferentes sucesos. Según esta concepción, el riesgo financiero es algo susceptible de control humano, incluso si este control sólo puede ser ejercido al modo como lo procuran las sutiles rutinas matemáticas de la programación dinámica estocástica que se emplean por ejemplo en ingeniería balística y aeronáutica (Sent, 1998). Para que la supervisión de las reservas preventivas bancarias pueda tener un efecto positivo de incremento del bienestar social, el hecho de la catástrofe financiera sólo puede ser concebido como algo que puede ser evitado. De suerte que algún nivel dado de reservas de capital impuesto por el regulador pueda ser definido como «seguro", y la gran mayoría de las pérdidas de negociación que lleguen a afectar la línea de flotación de un banco puedan ser atribuidas a errores de incumplimiento de los requisitos mínimos impuestos por el supervisor en materia de fiabilidad tecnológica de los modelos internos de control de riesgos. Bajo este marco interpretativo tradicional, ciertas prácticas de gestión financiera pueden ser calificadas de «defectuosas» y pueden buscarse responsabilidades legales de carácter individual por «mala gestión».

Pero si, como argumentan los críticos más radicales de la econometría financiera neoclásica, el movimiento de los precios especulativos es un proceso indeterminista de segundo orden (Mandelbrot, 1996), un fenómeno probabilístico «monstruoso» no susceptible de compresión algorítmica, entonces ninguna catástrofe financiera realmente acreedora de tal nombre puede ser prevenida a nivel individual ni tampoco a nivel colectivo. Por tanto no puede ser definido ningún nivel de reservas precautorias de capital bancario (ni siquiera una cobertura total de los activos) digno del calificativo «seguro». Y ningún daño ocasionado a los acreedores o los accionistas de un banco en la forma de una bancarrota instantánea puede realmente ser atribuido a una «mala gestión» del riesgo por parte de los administradores del banco. La responsabilidad humana queda aquí traducida al lenguaje del «fallo de las cosas», reino del accidente imprevisto y el daño inintencionado. Bajo este escenario teórico alternativo, no sorprende que los ejecutivos bancarios consideren que toda norma de supervisión pública que intente intervenir sobre la gestión privada del riesgo tiene un efecto netamente negativo sobre el bienestar económico colectivo.

Trágicamente confrontados con la dinámica estocástica hiperbólica de los precios especulativos en los mercados financieros, lo que precisan hoy de manera desesperada quienes tienen a su cargo las tareas cotidianas de mantenimiento administrativo de los dos constructos sociales gemelos que conforman el núcleo institucional de las economías capitalistas de mercado, el valor contable y el dinero-mercancia, es poder considerar esas dos entidades "como si efectivamente fueran invariantes, incluso aunque todos sabe[n] que no lo son en absoluto.» (Mirowski, 1991: 579). 


\section{CONCLUSIÓN}

La teoría económica matemática de la valoración de activos en equilibrio, una aventura intelectual con poco más de cuarenta años de vida, se ha consolidado como uno de los campos más dinámicos y respetados de la ciencia económica. Junto con el explosivo mercado de trabajo y los salarios «indecentes» que se pagan a cientos de jóvenes MBAs en finanzas matemáticas y computacionales, los Premios Nobel de Ciencias Económicas de 1991 y 1997 concedidos a Harry Markowitz, William Sharpe y Merton Miller por sus modelos pioneros de selección de carteras, valoración de riesgos y arbitraje, y a Robert C. Merton y Myron Scholes por sus esquemas de replicación y síntesis dinámica de activos derivados, evidencian de forma contundente el éxito científico, económico y político sin precedentes de este esotérico cuerpo de conocimiento social.

Por otro lado, las recientes catástrofes financieras asociadas con el comercio de productos derivados, algunas tan notables como la caída libre de la Bolsa de Nueva York en octubre de 1987 (Jacobs, 1999), la quiebra en 1994 de la multinacional Metallgessechschaft y de la hacienda pública del condado californiano de Orange (Jorion, 1995), o el colapso en 1995 de la mítica Banca Barings (Millman, 1996), han suscitado toda serie de preocupaciones y acusaciones en relación con los defectos científicos y los peligros tecnológicos de esta rama de la economía financiera aplicada que se ha dado en llamar «ingeniería financiera». ${ }^{14}$

La publicitada debacle en septiembre de 1998 del enorme hedge fund («fondo de cobertura», un fondo de inversiones en derivados financieros) LongTerm Capital Management (Dunbar, 2000) es tal vez el ejemplo más extremo que nos ofrece hasta el momento el laboratorio económico de la historia para medir el efecto devastador que puede llegar a tener esta extraña clase de riesgos financieros reflexivos en los que incurren los agentes por el hecho de emplear de forma intensiva y extensiva modelos matemáticos de valoración de instrumentos derivados para fines de negociación mercantil.

En las operaciones cognitivas de totalización estadística de eventos singulares se haya muchas veces el nudo gordiano de las disputas científico-políticas fundamentales de nuestro tiempo (Desrosières, 1993: 397ss.) -así la querella interminable sobre el origen de las desiguldadades sociales (Thévenot, 1990) o, a otro nivel, la controversia sobre la responsabilidad en los accidentes de trabajo (Dodier, 1994). Del reglaje o desreglaje procedimental de esta variedad característica de situaciones de pública puesta a prueba de la realidad de nuestra realidad social, depende pues, en buena medida, el perfil moral que

14 La reciente reedición actualizada de la investigación sociológica ya clásica de Charles Perrow sobre los «accidentes normales» o «accidentes sistémicos» que tienen lugar en entornos tecnológicos de alto riesgo, incluye un añadido final donde el autor defiende la pertinencia de su modelo de los accidentes inevitables producidos por «un error pequeño que interactúa con otro error pequeño» para el estudio los nuevos tipos emergentes de sistemas tecnológicos de alto riesgo durante los últimos 15 años. Junto con los desaguisados producidos por fallos de programación informática (como el fantasmagórico «efecto 2000). Perrow destaca el caso de las catástrofes financieras asociadas con la comercialización masiva de instrumentos de derivados. 
adoptan en última instancia las sociedades tecnológicas avanzadas (Boltanski y Chiapello, 1999: 402-411).

En un trabajo ya clásico, Meier y Short (1983) proporcionaron el primer argumento sociológico explícito que vinculaba la teoría criminológica crítica de la delincuencia de cuello blanco con el dilema, específico del diseño de políticas públicas, de cómo sostener el tejido de la confianza colectiva en un mundo permanentemente en riesgo de accidente, donde tanto la esperanza de un mayor bienestar económico futuro como el miedo de una macro-ruptura institucional son potenciados por la dinámica misma de innovación tecnológica. Dado que la vida industrial moderna, arguyen Meier y Short, es inherentemente riesgosa y por esa misma razón la conexión entre la acción intencional y sus consecuencias sociales observables es terriblemente ambigua, el acto de cualificar moralmente una determinada conducta profesional o corporativa de «negligente» (imprudencia bancaria) o incluso de «criminal» (fraude financiero), atribuyéndole así responsabilidad directa por los daños asociados con la objetivación de un tipo particular de riesgo social -en este caso el riesgo de mercado incurrido por los intermediarios financiero- constituye un tipo de juicio particularmente criticable desde un punto de vista sociológico. Más aún cuando, como es el caso con la industria global de derivados financieros, la intención innovadora constituye el factor esencial de lo que los actores consideran un comportamiento responsable.

La tesis que he intentado defender en este trabajo es que la afirmación inversa a ésta debe también ser cierta: puesto que la moderna ciencia (social) empírica es, a la vez que una empresa investigadora de alto riesgo, también una aventura profesional y organizacional con importantes consecuencias y, por tanto, con enormes responsabilidades a nivel colectivo, el hecho de disolver acríticamente toda sospecha de conducta negligente o claramente delictiva en el oscuro cajón de sastre del error cognitivo inintencionado, como hacen ciertas interpretaciones unilaterales de la teoría del riesgo de modelo, ha de ser considerado no menos controvertido.

\section{BIBLIOGRAFÍA}

Bernstein, P.L. (1992): Capital Ideas. Nueva York, Free Press.

Besen, S. \& Farrell, J. (1994): Choosing How to Compete. Journal of Economic Perspectives, Primavera, 117-31.

Boltanski, L. y Thévenot, L. (1991): De la justification. París, Gallimard.

- y Chiapello, E. (1999): Le nouvelle esprit du capitalisme. París, Gallimard.

Boyle, J. (1996): Shamans, Software and Spleens. Cambridge, MA, Harvard University Press.

Chateauraynaud, F. (1991): La faute profesionelle. París, Métailié.

CHEw, L. (1994): Shock Treatment. Risk, septiembre, 63-68.

Clarke L. y ShorT, J. (1993): Social Organization and Risk: Some Current Controversies, Annual Review of Sociology, 19, 375-99.

COMITÉ DE BASILEA (1988): International Convergence of Capital Measurement and Capital Standards. Basilea.

- (1996a): Amendment to the Capital Accord to Incorporate Market Risks. Basilea. 
- (1996b): Supervisory framewok for the use of «backtesting» in conjuction with the internal models approach to market risk capital requirements. Basilea.

Derman, E. (1996a): Model Risk. Risk, mayo, 34-37.

- (1996b): The Value of Models and Modelling Value. Journal of Portfolio Management, 22, 106-144.

Desrosières, A. (1993): La politique des grands nombres. París, La découverté.

Dodier, N. (1994): Causes et mises en cause. Innovation sociotechnique et jugement moral face aux accidents du travail. Révue française de sociologie, 35, 251-281.

- (1995). Les hommes et les machines. Paris, Métailié.

- y BASZANGER, I. (1997): Totalisation et altérité dans l'enquête ethnographique. Révue française de sociologie, 38, 37-66.

Douglas, M. (1996): La aceptabilidad del riesgo según las ciencias sociales, Barcelona: Paidós.

DuffIE, D. y PAN, J. (1997): An Overview of Value at Risk. Journal of Derivatives, Primavera, 7-49.

Dunbar, N. (1998): The Accord is Dead - Long Live the Accord. Risk, octubre, 9.

- (1999): This is the way the world ends. Risk, diciembre, 26-32.

- (2000): Inventing Money. New York: Wiley.

Falloon, W. (1998): Rogue Models and Model Cops. Risk, septiembre, 24-31. - (1999): Patent Power: Who Owns the Ideas that Drive Derivatives? Risk, diciembre, 22-27.

GIBSON, R. et. al. (1998): Interest rate model risk: What are we talking about? HEC Lausanne, WP n. ${ }^{\circ} 9803$.

Grafton, A. (1990): Forgers and Critics. Princeton, NJ, Princeton University Press.

Gusfield, J. (1981): The Culture of Public Problems. Drinking-Driving and the Symbolic Order, Chicago, IL: The University of Chicago Press.

Heimer, C. (1988): Social Structure, Psychology, and the Stimation of Risk. Annual Review of Sociology, 14, 491-519.

IZQUIERDO, A.J. (1998): El declive de los grandes números. Empiria, 1, 51-84.

- (1999a): Antropismo social, reflexividad estadística y liberalismo avanzado. En

R. Ramos y F. García-Selgas (dirs.) Globalización, riesgo, reflexividad. Madrid, CIS, 521-556.

- (1999b): De la fiabilidad. Tesis doctoral inédita. Universidad Complutense de Madrid.

JACOBS, B. (1999): Capital Ideas and Market Realities. Londres, Blackwell.

Jorion, Ph. (1995): Big Bets Gone Bad. Nueva York, Academic Press.

- (1997a): Value at Risk. Chicago, Irwin.

- (1997b): In Defense of VaR. Derivatives Strategy, enero.

KAYE, B. (1995): Science and the Detective. Selected Reading in Forensic Science. Nueva York, VCH.

Krugman, P. (1997): Desarrollo, geografía y teoría economómica. Barcelona, Bosch.

LEE, R. (1998): What is an Exchange? Oxford, Oxford University Press.

Mandelbrot, B. (1963): New Methods in Statistical Economics. Journal of Political Economy, 71, 421-440.

- (1996): Del azar benigno al azar salvaje. Investigación y Ciencia, diciembre, 14-20.

- (1997): Fractals and Scaling in Finance. Nueva York, Springer.

- (1999): A Multifractal Walk down Wall Street. Scientific American, febrero, 70-73.

Meier, R. y ShorT, J. (1983): The Consequences of White-Collar Crime. En H. Edelhertz (ed.) White-Collar Crime: An Agenda for Research. Lexington, MA, Lexington Books, 23-49. 
Merton, R.C. (1995): Financial Innovation and the Management and Regulation of Financial Institutions. Journal of Banking and Finance, 19, 461-481.

MILLMAN, G.J. (1996): Especuladores internacionales: los nuevos vándalos. Bilbao, Ediciones Deusto.

Mirowski, P. (1991a): Postmodernism and the Social Theory of Value. Journal of Postkeynesian Economy, 13, 565-582.

Pérez-Campanero, J. (1995): La gestión del riesgo de mercado. ICE, diciembre, 65-78.

Perrow, Ch. (1999): Normal Accidents: Living with High-Risk Technologies [1984]. Princenton, NJ, Princenton University Press.

RHODE, W. (1998): Amending the Accord. Risk, septiembre, 46-51.

SCHEPPELE, K.L. (1991): Law Without Accidents. En P. Bourdieu y J.S. Coleman (eds.) Social Theory For a Changing Society. Boulder, CO, Westview Press, 267-297.

SENT, E-M. (1998): Engineering Economic Dynamics. En J. Davis (ed.). New Economics and Its History. Durham y Londres, Duke University Press, 41-62.

SHAPIRO, S.P. (1987): The Social Control of Impersonal Trust. American Journal of Sociology, 93, 623-658.

SHILLER, R.J. (2000): Irrational Exuberance. Princenton, NJ, Princenton University Press. Shimomura, T. \& Markoff, J. (1997): Takedown. Madrid, Aguilar.

Soros, G. (1994): The Alchemy of Finance. Nueva York, Wiley.

STIX, G. (1998): Un cálculo del riesgo. Investigación y ciencia, julio, 24-30.

Swary, I. \& Topf, B. (1993): La desregulación financiera global. México DF, Fondo de Cultura Económica.

TALEB, N. (1997a): Interview: The World According to Nassim Taleb. Derivatives Strategy, enero.

- (1997b) Against Value at Risk (paper available on line at http://pwl.netcom. com/@ntaleb/jorion.htm)

Thévenot, L. (1990): La politique des statistiques. Les origines sociales des enquêtes de mobilité social. Annales ESC, 6, 1275-1300.

TORRERO, A. (1993): La crisis del sistema bancario: lecciones de la experiencia de Estados Unidos. Madrid, Cívitas.

WALTER, C. (1996): Une histoire du concept d'efficience sur les marchés financiers. Annales HSS, 4, 873-905.

\section{RESUMEN}

Este trabajo explora sociológicamente el problema, a la vez cognitivo y político-moral, del riesgo de modelo. Como lo han definido convencionalmente los profesionales de la ingeniería financiera, el riesgo de modelo refiere a perdidas monetarias producidas por el empleo de modelos matemáticos defectuosos de medición y control de riesgos de inversión. La emergencia reciente de este genuino riesgo industrial «de segundo orden», se asocia con la dinámica hiper-competitiva y exponencialmente innovadora de los mercados de servicios financieros avanzados. El riesgo de modelo es de hecho un componente esencial en la valoración y el comercio de productos financieros «derivados» como los futuros, las opciones y las permutas. De forma más general, el riesgo de modelo supone un desafío para la fiabilidad de los sistemas bancarios de control interno de riesgos de negociación bursátil, planteando en última instancia problemas decisivos para la eficacia y la credibilidad de los sistemas de supervisión 
pública de riesgos bancarios. En respuesta a este desafío, y bajo la apariencia de un proceso de desregulación administrativa destinado a gestionar de modo más flexible los nuevos riesgos de segundo orden, durante la década de los 90 tuvo lugar una reforma radical de la metodología tradicional de los sistemas públicos de supervisión de riesgos bancarios. Dicha reforma arroja como resultado provisional el triunfo de una nueva generación de procedimientos burocráticos indirectos de verificación y certificación pública, cuyo representante más genuino son las auditorías de calidad de sistemas de control de riesgos.

\begin{abstract}
This paper explores in a sociological way the problem, at the same time cognitive and political (moral), of model risk. As conventionally defined by financial engineers and traders, model risk refers to financial losses produced by the use of flawed mathematical models for the measurement and control of investment risks. The recent emergence of this genuine type of «second-order» industrial risk, is associated with the hyper-competitive, exponentially innovative dynamics characteristic of markets for advanced financial services. Model risk is in fact a key factor in the pricing and trading of "derivative» financial products, such as futures, options and swaps. At a more basic level, model risk defies the reliability of banks' internal trading risk control systems, eventually posing decisive questions of efficacy and credibility to public supervisory systems of banking risks. To answer this defy, and under the appearance of a deregulatory process intended to manage in a more flexible way this new second-order type of financial risks, the decade of the $90 \mathrm{~s}$ saw a radical reform of the traditional methodology of public banking supervisory systems. This reform has had as a provisional result the triumph of a new generation of indirect administrative procedures for public verification and certification, which most developed exemplar are risk control systems quality audits.
\end{abstract}

